\title{
Enhancement of UV Radiation by Cloud Effect in NE of Brazil
}

\author{
Chigueru Tiba $^{1}$ and Sérgio da Silva Leal ${ }^{2}$ \\ ${ }^{1}$ Nuclear Energy Department of the Federal University of Pernambuco (UFPE), Av. Prof. Luiz Freire, 1000-CDU, 50.740-540 Recife, \\ PE, Brazil \\ ${ }^{2}$ Federal Institute of Education, Science and Technology of Pernambuco (IFPE), São Paulo, SP, Brazil
}

Correspondence should be addressed to Chigueru Tiba; tiba@ufpe.br

Received 27 April 2017; Accepted 21 June 2017; Published 24 July 2017

Academic Editor: Mark van Der Auweraer

Copyright (c) 2017 Chigueru Tiba and Sérgio da Silva Leal. This is an open access article distributed under the Creative Commons Attribution License, which permits unrestricted use, distribution, and reproduction in any medium, provided the original work is properly cited.

\begin{abstract}
This paper reports a detailed analysis of ground-based measurements of cloud-enhanced global solar and UV radiation in NE Brazil in the city of Recife. It was found that (a) the phenomenon of UV enhancement, above clear sky model, is not uncommon and that it occurs on at least eight months; (b) the cumulative duration can reach 13 minutes; (c) there is a clear seasonal effect, and the probability of occurrence on a monthly basis shows two peaks, one in March and another in October; and (d) the most extreme UV radiation was $70.4 \mathrm{~W} / \mathrm{m}^{2}$, approximately $6 \mathrm{~W} / \mathrm{m}^{2}$ higher than the clear sky UV radiation. The extreme values should be taken into account in the study of effects related to the UV index and biological effects. Two statistical models also were elaborated, to estimate the UV solar radiation, in which the first is for all sky conditions and the second exclusively for situations where the global solar radiation is equal to or higher than $1367 \mathrm{~W} / \mathrm{m}^{2}$, resulting from the enhancement effect caused by a particular configuration of the clouds. The statistical indicatives for both models presented, respectively, MBE\% of 3.09 and $0.48 \%$ and RMSE $\%$ of 15.80 and $3.90 \%$.
\end{abstract}

\section{Introduction}

The spectre of ultraviolet radiation (UV) that reaches the top of the terrestrial atmosphere covers the wavelength from 100 to $400 \mathrm{~nm}$ and is normally subdivided in three intervals: UVA (320-400 nm), UVB $(280-320 \mathrm{~nm})$, and UVC $(100-280 \mathrm{~nm})$. The UVA and UVB radiations reach terrestrial surface; however, UVC is strongly absorbed by the atmosphere. UV radiation stimulates the production of vitamin $\mathrm{D}$ and contributes to decontamination process of rivers and lakes, being considered important for the health of human beings. However, the excess of exposition to UV radiation may cause several harmful effects on human health, such as burns, freckles, premature aging, cataract, and skin cancer [1]. Estimates of the World Health Organization [2] point out that cataract is the most probable cause for worldwide visual loss and the responsible for half of the blind individuals. According to the National Cancer Institute [3], it is estimated that nonmelanoma skin cancer (180 thousand new cases), in the year of 2016, had the most incident in the Brazilian population.

The very close geographic location to the equator line is the cause of high levels of radiation (global and UV) practically during the entire year in the State of Pernambuco, particularly in the capital Recife. Studies previously performed showed that the levels of global radiation incident on the terrestrial surface can reach in determined conditions and in determined intervals, higher levels than the ones detected in the clear sky and even extraterrestrial conditions. This occurs in determined spatial configurations, when the kind, the density, and the coverage of clouds (between $50 \%$ and $90 \%$ of the sky), along with clear sky regions, result in a solar radiation enhancement above predicted conditions for clear sky $[4,5]$. The enhancement lasts for a significant range of time (6 minutes in average) and that can bring risks to individuals and materials when exposed without protection. 
TABLE 1: Measurement station of the global and the erythemic solar radiation.

\begin{tabular}{|c|c|c|c|c|c|c|}
\hline \multirow{2}{*}{ Station } & \multirow{2}{*}{ Mesoregion } & \multicolumn{3}{|c|}{ Geographic coordinates } & \multirow{2}{*}{ Climate } & \multirow{2}{*}{ Measurement period } \\
\hline & & Lat. & Long. & Alt. (m) & & \\
\hline Recife-PE & Metropolitan & $-8^{\circ} 03^{\prime}$ & $-34^{\circ} 55^{\prime}$ & 7 & Tropical humid & January to December 2011 \\
\hline
\end{tabular}

TABLE 2: Linke turbidity index and the aerosol optical depth for 700 and $440 \mathrm{~nm}$.

\begin{tabular}{lccc}
\hline Month & $\begin{array}{c}\text { Linke turbidity } \\
\text { index }\left(\mathrm{TL}_{2}\right)\end{array}$ & $\begin{array}{c}\text { Optical depth } \\
(700 \mathrm{~nm})\end{array}$ & $\begin{array}{c}\text { Optical depth } \\
(500 \mathrm{~nm})\end{array}$ \\
\hline January & 4.6 & 0.19 & 0.33 \\
February & 4.0 & 0.14 & 0.24 \\
March & 4.0 & 0.14 & 0.24 \\
April & 4.6 & 0.19 & 0.33 \\
May & 4.4 & 0.17 & 0.30 \\
June & 4.6 & 0.19 & 0.33 \\
July & 4.2 & 0.16 & 0.27 \\
August & 3.9 & 0.13 & 0.23 \\
September & 4.2 & 0.16 & 0.27 \\
October & 4.1 & 0.15 & 0.26 \\
November & 3.9 & 0.13 & 0.23 \\
December & 4.8 & 0.21 & 0.37 \\
Annual & 4.3 & 0.16 & 0.28 \\
\hline
\end{tabular}

\section{Material and Methods}

2.1. Measurement Station. Table 1 shows the global radiation and UV $(\mathrm{A}+\mathrm{B})$ measurement station, along with its geographical coordinates, climatic characteristics, and measurement periods.

To measure global solar radiation, a PSP pyranometer (Precision Spectral Pyranometer) Eppley was used, which the precision is $3 \%$, operation range is from 300 to $3000 \mathrm{~nm}$, and is considered by WMO $[6,7]$ as a first class instrument. The UV $(\mathrm{A}+\mathrm{B})$ solar radiation measurement was performed with a TUVR radiometer (The Total Ultraviolet Radiometer) which the precision is $<5 \%$ [8], from the manufacturer Eppley. The TUVR measures the ultraviolet radiation for the wavelength range between 295 and $385 \mathrm{~nm}$. Both pyranometers were new and factory calibrated, and none showed important driftage when compared with a secondary standard CMP22 pyranometer from Kipp and Zonen and a new TUVR, after one year of use. The radiometers were coupled to a data acquisition system from Campbell, model CR-1000X.

2.2. Extraterrestrial UV Solar Radiation. The extraterrestrial UV solar radiation in the horizontal plane for a determined hour can be calculated in a similar way to extraterrestrial global solar radiation through the expression

$$
\begin{aligned}
\mathrm{I}_{0 \mathrm{UV}}= & I_{\mathrm{SC}}(\mathrm{UV})\left[1+0.033 \cos \left(\frac{360 n}{365}\right)\right] \\
& \cdot[\cos \delta \cos L \cos h+\operatorname{sen} \delta \operatorname{sen} L],
\end{aligned}
$$

where $I_{\mathrm{SC}}(\mathrm{UV})=80.83 \mathrm{~W} \mathrm{~m}^{-2}$ (solar constant UV). $n$ is the julian day. $L$ is the local latitude. $\delta$ is the declination. $h$ is the hour angle.

2.3. Ultraviolet Solar Fraction $F_{U V}$. The relation between ultraviolet and global radiation for a given location results in the ultraviolet solar fraction $F_{\mathrm{UV}}$. The knowledge of the $F_{\mathrm{UV}}$ is important to estimate the ultraviolet radiation in places where there are no data on global solar radiation. Many researchers proposed models to estimate UV radiation from global radiation [9-11]. In these cases, ultraviolet radiation can be easily calculated through the following expression:

$$
I_{\mathrm{UV}}=F_{\mathrm{UV}} \cdot I_{\mathrm{G}}
$$

where $I_{\mathrm{UV}}$ is the ultraviolet irradiation on the terrestrial surface and $I_{\mathrm{G}}$ is the global irradiation, both on horizontal plane and in minute scale.

2.4. Clear Sky Model. To estimate the curves of global and UV radiations in Recife, considering a clear sky condition, a computational parametric model SPECTRAL2 was used [12]. The model requires entry data, such as aerosol optical depth (AOD) at $500 \mathrm{~nm}$, ozone concentration, latitude, longitude, and precipitable water.

The calculation of aerosol optical depth was performed by the inversion of the empirical equation [13], (3). The empirical expression of Molineaux is based on Linke turbidity index for the air mass $2\left(\mathrm{TL}_{2}\right)$, optical depth of water vapor, and clean and dry atmosphere. The aerosol optical depth is determined that way for the wavelength of $700 \mathrm{~nm}$ :

$$
\mathrm{T}_{\mathrm{L} 2}\left(\Delta_{a}, W\right)=(9.4+0.9 * m) *\left(\Delta_{c d a}+\Delta_{W}+\Delta_{a}\right),
$$

where $\Delta_{a}$ is the aerosol optical depth. $\Delta_{c d a}$ is the panchromatic optical depth of a clean and dry atmosphere, which is given by

$$
\Delta_{c d a}=-0.101+0.235 * m^{-0.16},
$$

where $m$ is the air mass $(m=2)$ and $\Delta_{W}$ is the panchromatic water vapor optical depth.

$$
\Delta_{W}=0.12 * m^{-0.55} * W^{0.34},
$$

where $W$ is the precipitable water contained in the atmosphere $(\mathrm{cm})$.

The $\mathrm{TL}_{2}$ calculation was based on a long time series of daily solar radiation (over 5 years), where the maximum daily solar radiation for each month and each year was chosen. For each month, a clear sky model was processed for a $\mathrm{TL}_{2}$, ranging from 2 to 8 generating 12 monthly average values of $\mathrm{TL}_{2}$ for Recife [14]. 


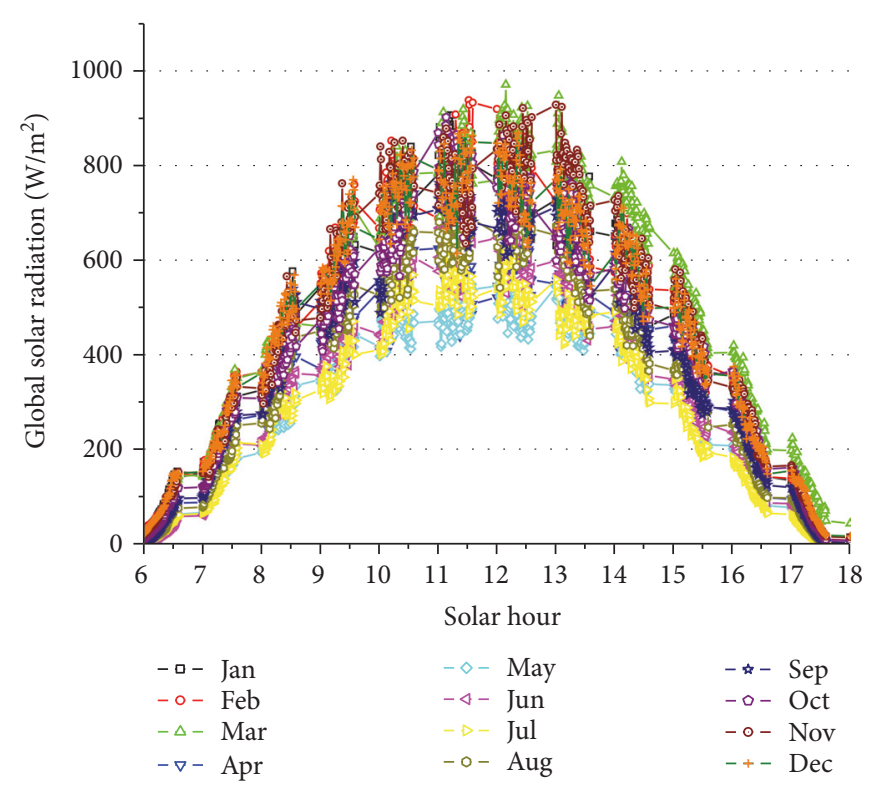

(a)

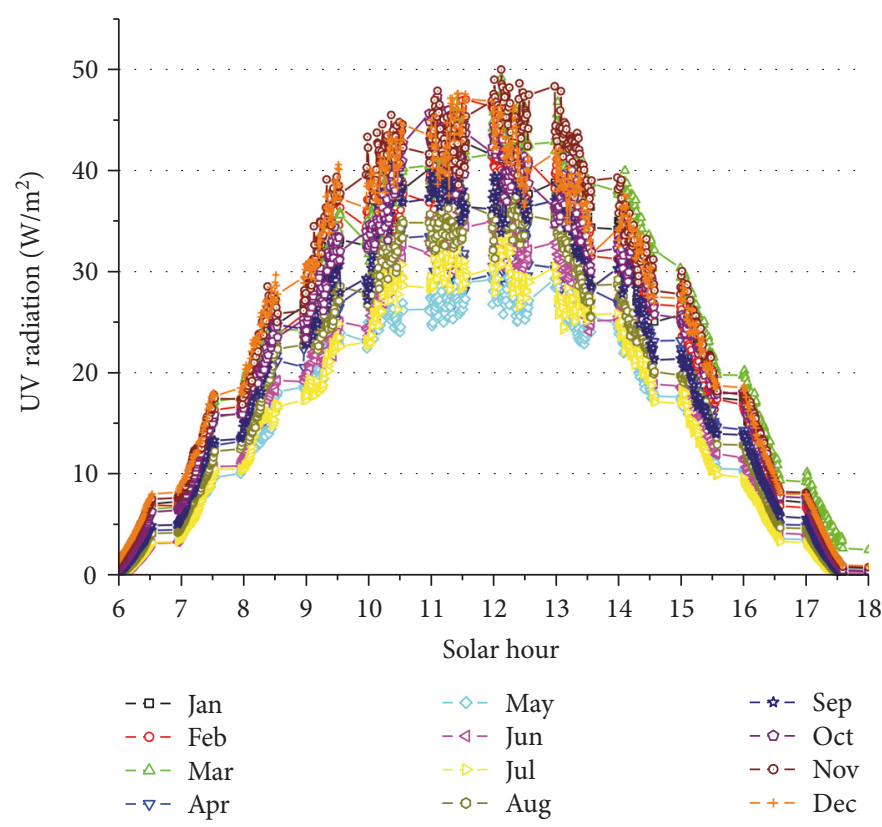

(b)

Figure 1: Global solar (a) and UV (A + B) radiation (b) monthly average in minute scale.

Average julian days were considered to represent the clear sky days of each month of the year of 2011. For these days, the ozone levels were determined, through NASA satellite data, Total Ozone Mapping Spectrometer (TOMS), considering the average of the last three years.

The aerosol optical depth of $700 \mathrm{~nm}$ was translated into a random wavelength $\lambda_{1}$ using the empirical expression:

$$
\alpha=-\frac{\ln \left(\tau_{a 2} / \tau_{a 1}\right)}{\ln \left(\lambda_{2} / \lambda_{1}\right)},
$$

where $\alpha=$ Angstrom exponent. $\tau_{a 2}$ is the optical depth calculated by the Molineaux formula. $\tau_{a 1}$ is the translated optical depth at $\lambda_{1} . \lambda_{2}$ and $\lambda_{1}$ are wavelengths.
The Angstrom exponent $\alpha$ for the wavelength range from 440 to $675 \mathrm{~nm}$ was experimentally determined in several urban locations and has an average value of 1.75 [15].

Table 2 shows the Linke turbidity index value for the air mass 2 obtained using the inverse model of clear sky of ESRA [16], the aerosol optical depth at $700 \mathrm{~nm}$ and finally the aerosol optical depth at $500 \mathrm{~nm}$.

\section{Results and Discussions}

3.1. UV $(A+B)$ Radiation Enhancement by Clouds. The daily values of UV $(A+B)$ and global solar radiation measured between January 1, 2011 and December 31, 2011, 

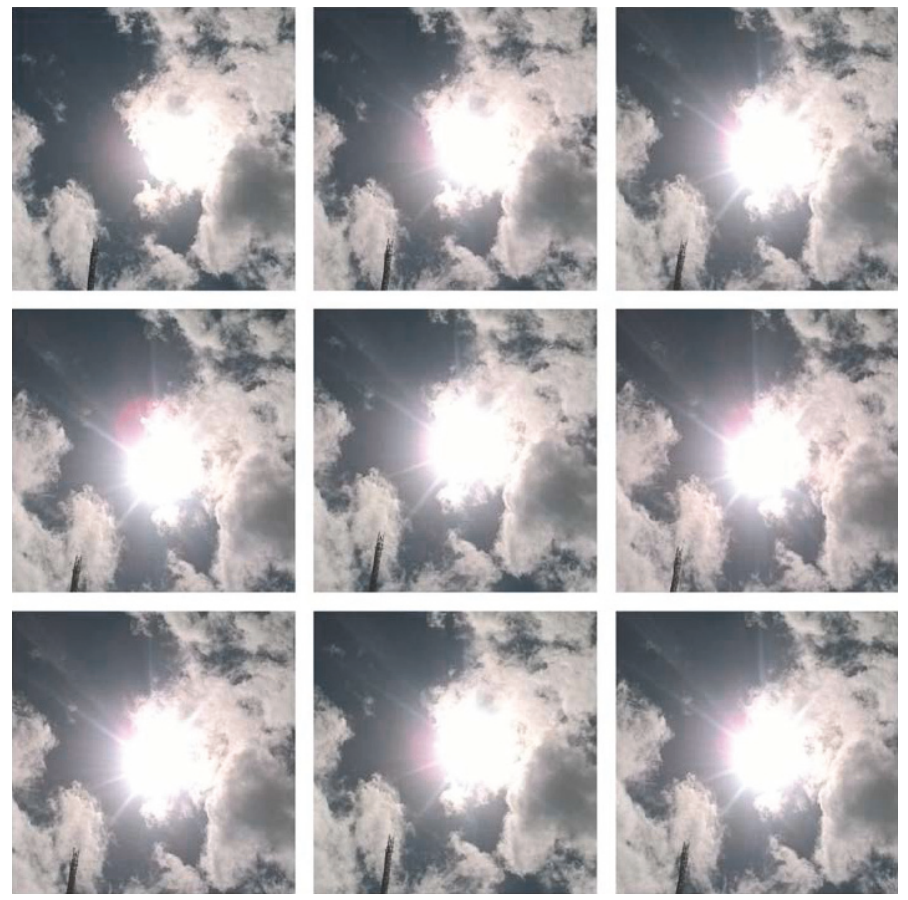

FIgURE 2: Typical configuration of the sky that can lead to a solar radiation enhancement effect.

in minute scale, are shown in Figures 1(a) and 1(b). A strong influence of seasonal effect on the behavior of the curves is observed with minimum in May and maximum in March.

The daily measurements performed showed that in some sky configurations, such as, those shown in Figure 2, global radiation exceeds the clear sky levels of radiation and even the levels of extraterrestrial radiation. In parallel, the levels of UV radiation present the same behavior, although the maximum values do not reach the extraterrestrial UV radiation values. This occurs due to a larger relative absorption of solar radiation in the UV spectrum.

Figures 3(a) and 3(b) show, respectively, the daily profiles of clear sky global solar and $\mathrm{UV}(\mathrm{A}+\mathrm{B})$ radiation for each month. The profiles were generated with SPECTRAL2 for the city of Recife. Maximum values are expected for the month of February, reaching on average, respectively, $1064 \mathrm{~W} / \mathrm{m}^{2}$ and $66 \mathrm{~W} / \mathrm{m}^{2}$ at midday.

In Figures 4(a) and 4(b), the cloud enhancement effect can be seen in the behavior of global solar and UV $(A+B)$ radiation for the day of October 9, where the extreme levels of radiation between the intervals from 11:43 to $11: 44$ and at $13: 14 \mathrm{~h}$ stand out. In these intervals, global radiation reached the maximum value of $1434 \mathrm{~W} / \mathrm{m}^{2}$ surpassing the value of radiation at the top of the atmosphere. Regarding the clear sky model, 34 occurrences surpassed the maximum value of $1049 \mathrm{~W} / \mathrm{m}^{2}$, reached at midday. The UV $(\mathrm{A}+\mathrm{B})$ radiation reached the value of $70 \mathrm{~W} / \mathrm{m}^{2}$, surpassing the $64 \mathrm{~W} / \mathrm{m}^{2}$ expected considering the clear sky curve for the month of October, Figure 4(b). For this extreme situation, this implicates in an ultraviolet index (UVI) value higher than 15 [17]. Similar analysis was performed for the day of January 15, as can be seen in Figures 4(c) and 4(d).

The results showed that global solar radiation enhancement, due to specific cloud spatial configuration, is higher when compared to UV radiation enhancement.

It was observed that the phenomenon is very common and distributed throughout the year. In the year 2011, values for global radiation higher than $1367 \mathrm{~W} /$ $\mathrm{m}^{2}$ were observed in the months of January, February, March, April, May, October, November, and December, totaling to 122 occurrences. However, if the global radiation levels that surpass the maximum values predicted for a clear sky day are considered, the occurrences now total to 68,904 , that is, 68,904 minutes, or $26 \%$ from the total measurements performed in the year of 2011. In the case of UV radiation, this percentage drops to $7 \%$. Table 3 shows the number of events (event is the minute where the enhancement phenomenon occurs) monthly and annually. Even with a small percentage when compared to the total samples obtained, the levels of UV radiation reach significant values that can cause harmful effects to living beings and materials that are exposed to this radiation.

Figure 5 shows the probability of occurrences of the UV solar radiation enhancement phenomenon in function of the differences between measured and modeled UV radiation $\Delta\left(\mathrm{W} / \mathrm{m}^{2}\right)$, considering the daily period from 09:00 AM to 3:00 PM.

The graph shows that $46 \%$ (1816 occurrences) of all measurements performed in that period surpass the clear sky curve in $1 \mathrm{~W} / \mathrm{m}^{2}(\Delta=1)$. 


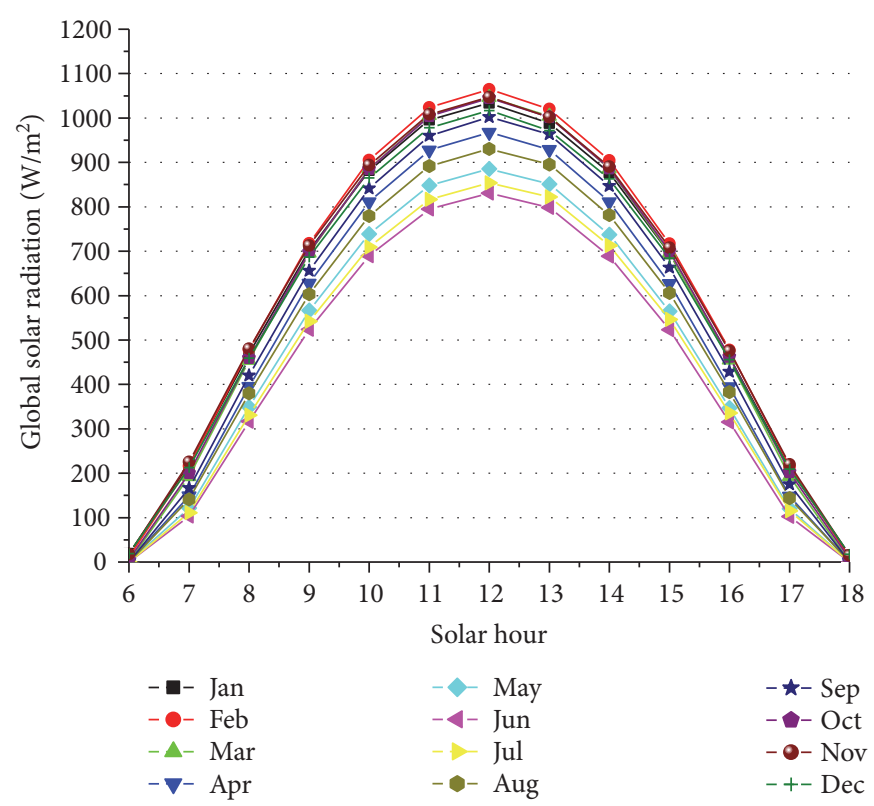

(a)

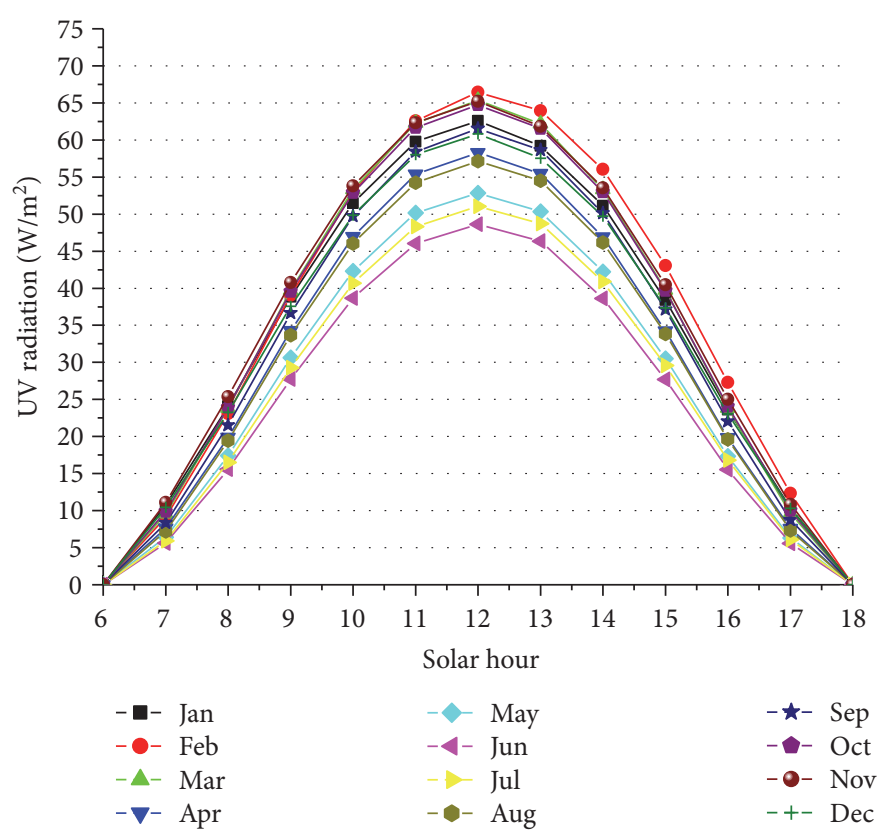

(b)

FIGURE 3: Daily profiles of global solar radiation (a) and UV $(A+B)$ radiation (b) estimated with SPECTRAL2 for a clear sky day throughout the months of the year.

Table 4 shows the maximum duration of consecutive minutes of UV radiation measured, which surpassed the clear sky curve above $1 \mathrm{~W} / \mathrm{m}^{2}$, in addition to maximum deviation $\left(\Delta_{\max }\right)$ and monthly maximum UV radiation $\left(U V_{\max }\right)$ occurred in consecutive interval of time.

For these situations, the UV radiation, in some minute, surpassed clear sky curve in $6.21 \mathrm{~W} / \mathrm{m}^{2}$ in the month of March, reaching the plateau of $70.39 \mathrm{~W} / \mathrm{m}^{2}$. The maximum duration period of lens effect was observed in December, 13 minutes.
The study also showed that in the year of 2011, levels of maximum global radiation of $1491 \mathrm{~W} / \mathrm{m}^{2}$ were detected and, in the case of UV radiation, maximum values of $72 \mathrm{~W} / \mathrm{m}^{2}$. The monthly accumulated distribution of global and UV radiation can be seen in Figures 6(a) and 6(b). These curves allow us to estimate the minute percentage in which radiation surpassed a determined value in a determined month. In the case of Figures $6(\mathrm{~b})$ and $6(\mathrm{~d})$, it can be stated that $10 \%$ of the minutes of the year presented levels of global and UV radiation equal to or higher than $1000 \mathrm{~W} / \mathrm{m}^{2}$ and $50 \mathrm{~W} / \mathrm{m}^{2}$, respectively. 


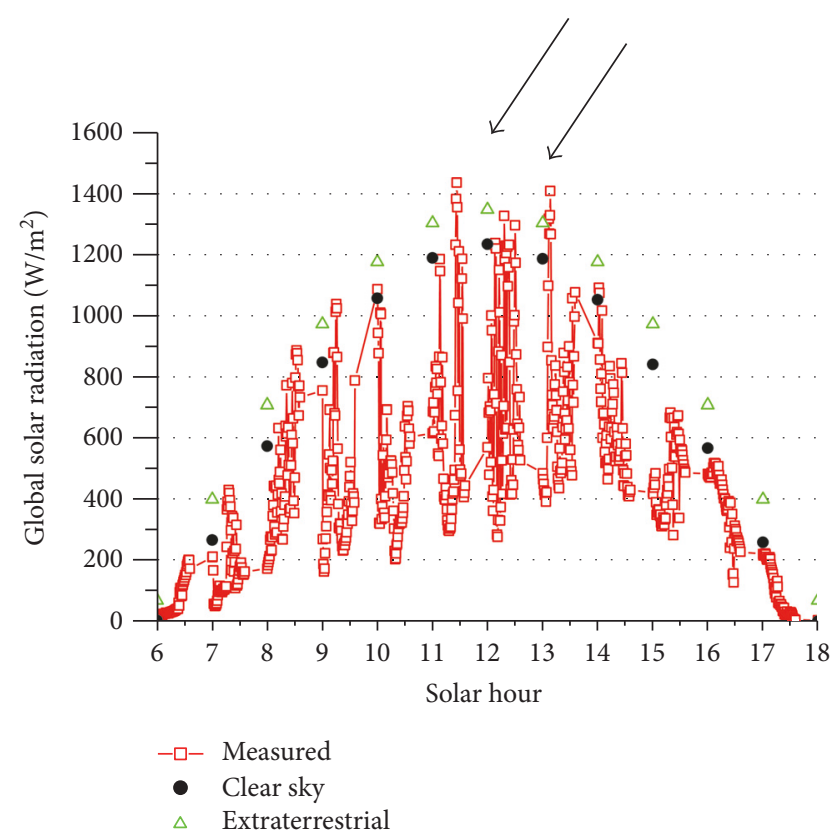

(a)

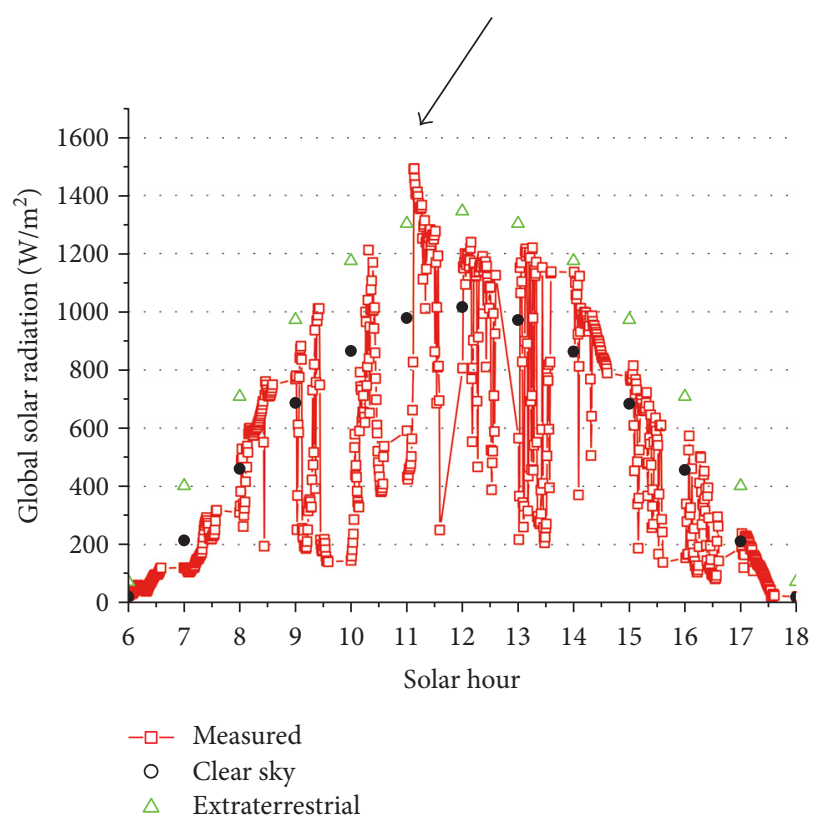

(c)

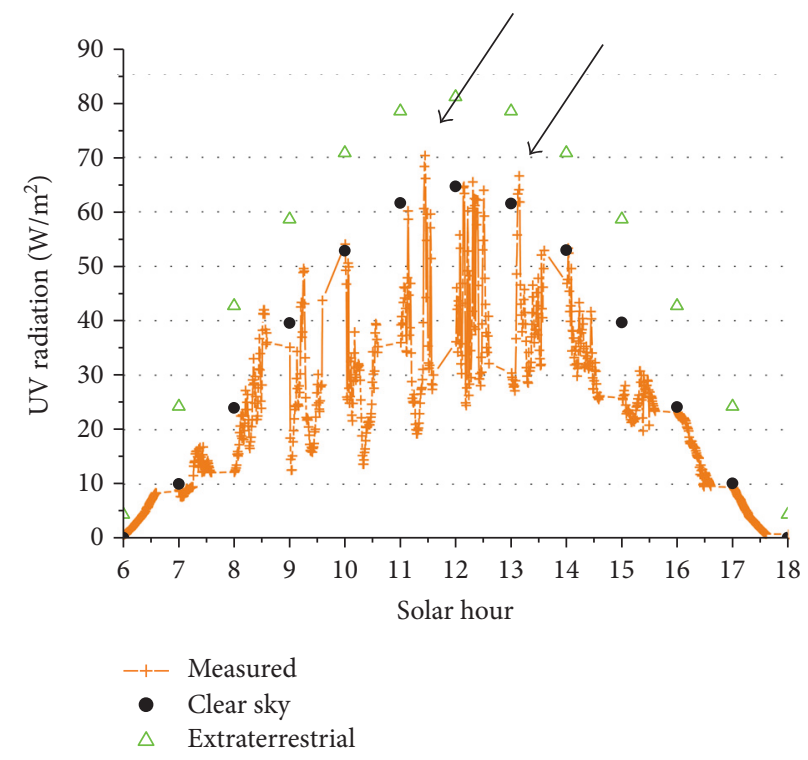

(b)

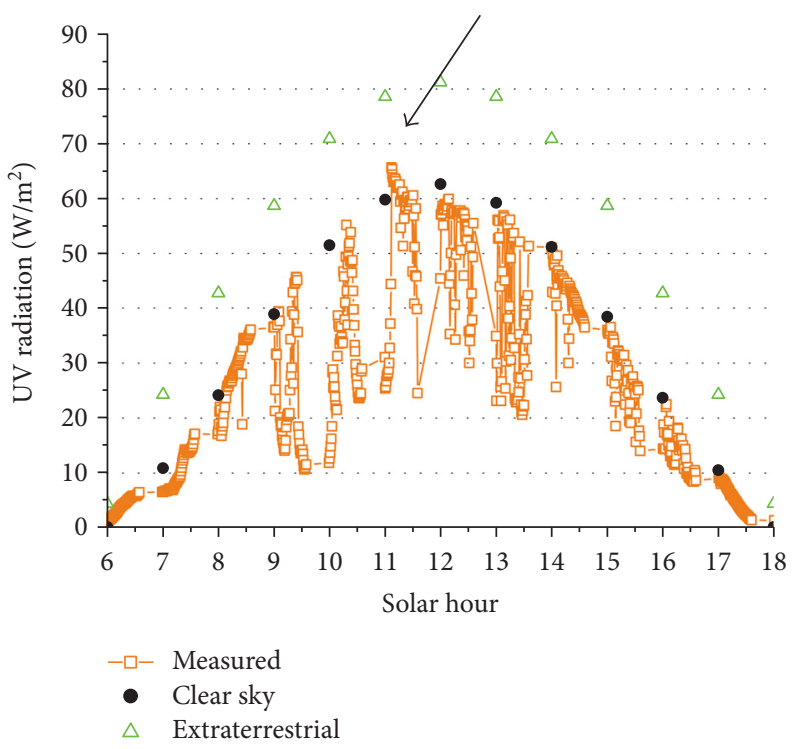

(d)

FIgURE 4: Behavior of global solar and UV $(A+B)$ radiation for the day of October 9 (a and b) and January 15, 2011 (c and d).

3.2. Modeling of the Equation for the Estimative of UV Radiation in Minute Scale. The statistical properties of UV solar radiation in a minute scale were analyzed as follows: the measurements in a minute scale were randomly mixed and divided in two different sets. The first set was used to model the UV radiation estimation equation in function of global radiation. The second set was used to validate the model by making the statistical comparisons between the experimental and the modeled values by means of the statistical indicatives MBE and RMSE:

$$
\begin{aligned}
\mathrm{MBE} & =100 \frac{\sum_{n}\left(I_{\mathrm{UV}-\text { calculated }}-I_{\mathrm{UV}-\text { measured }}\right)}{\sum_{n} I_{\mathrm{UV} \text {-measured }}} \%, \\
\mathrm{RMSE} & =100 \frac{\sqrt{\sum_{n}\left(\left(I_{\mathrm{UV}-\text { calculated }}-I_{\mathrm{UV}-\text { measured }}\right)^{2} / n\right)}}{\sum_{n}\left(I_{\mathrm{UV}-\text { measured }} / n\right)} \% .
\end{aligned}
$$

For modeling the UV radiation estimation equation, the period between 6:00 AM and 6:00:PM of the selected days 
TABLE 3: Number of events above clear sky and extraterrestrial model for global solar and UV radiation.

\begin{tabular}{lcccc}
\hline Month & $\begin{array}{c}\text { Number of events above } \\
\text { extraterrestrial global } \\
\text { radiation }\end{array}$ & $\begin{array}{c}\text { Number of events above } \\
\text { extraterrestrial UV radiation }\end{array}$ & $\begin{array}{c}\text { Number of events above clear } \\
\text { sky global radiation model }\end{array}$ & $\begin{array}{c}\text { Number of events above clear } \\
\text { sky UV radiation model }\end{array}$ \\
\hline January & 28 & 0 & 6922 & 2677 \\
February & 20 & 0 & 5770 & 1782 \\
March & 25 & 0 & 8118 & 998 \\
April & 2 & 0 & 5146 & 1419 \\
May & 1 & 0 & 3638 & 535 \\
June & 0 & 0 & 5238 & 1710 \\
July & 0 & 0 & 3783 & 978 \\
August & 0 & 0 & 4437 & 313 \\
September & 0 & 0 & 4766 & 443 \\
October & 30 & 0 & 6129 & 1087 \\
November & 5 & 0 & 6948 & 1559 \\
December & 11 & 0 & 8009 & 4092 \\
Total & $122(2.03 \mathrm{~h})$ & 0 & $68,904(1148.4 \mathrm{~h})$ & $17,593(293.2 \mathrm{~h})$ \\
\hline
\end{tabular}

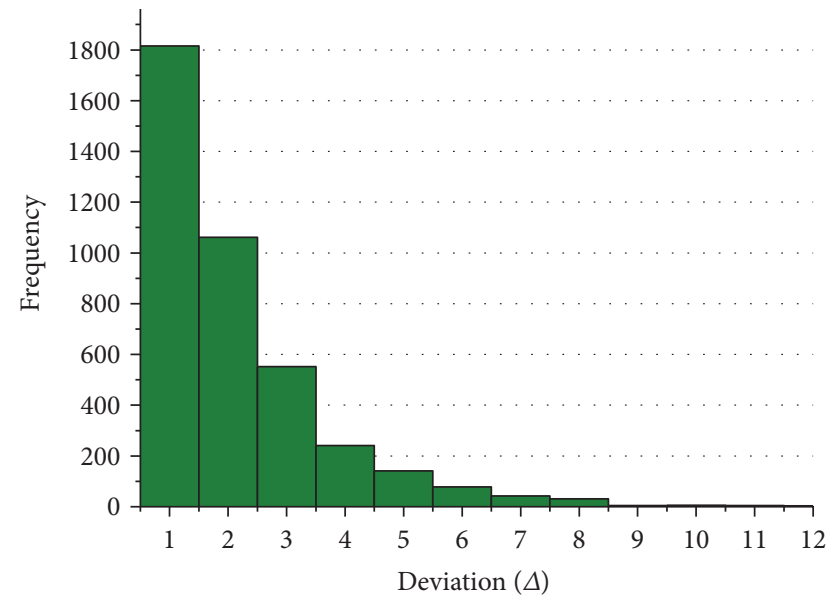

Figure 5: Occurrence probability of the event for the differences between measured and modeled UV solar radiation (clear sky).

was considered. The correlation between global and UV $(\mathrm{A}+\mathrm{B})$ radiation in minute scale, according to Figure 7 , resulted in the following expression:

$$
I_{\mathrm{UV}}=0.052 \cdot I_{\mathrm{G}} \text {. }
$$

The statistical indicative presented a MBE\% of 3.09\% and a RMSE\% of $15.80 \%$; however, considering only the occurrences where global radiation values surpassed the plateau of $1367 \mathrm{~W} / \mathrm{m}^{2}$, due to the cloud enhance effect, the correlation resulted in a ultraviolet solar fraction 10\% lower, as can be seen in the following expression:

$$
I_{\mathrm{UV}}=0.046 \cdot I_{\mathrm{G}} \text {. }
$$

The cloud enhance effect provides a more intense enhancement in the global radiation when compared to the UV radiation enhancement. For this kind of occurrence, the same statistical indicative presented a
$\mathrm{MBE} \%$ of $0.48 \%$ and a RMSE\% of $3.90 \%$. It is worth noting that the models were statistically tested with a second distinguished data group, exercising no influence on the obtained results. Figure 8 shows the comparison between the experimental values of the second group and the values estimated by the model, considering random samples.

\section{Conclusions}

The global and the UV $(A+B)$ radiation measurements performed in the described period for the city of Recife confirmed a strong hourly and seasonal dependency typical of the Northeast region of Brazil. Higher values are normally reached at midday and in the periods of low cloudiness (summer). However, in some situations, not necessarily at midday, and for a period of a few minutes, the global radiation surpasses the levels of extraterrestrial radiation due to the cloud enhance effect. In these situations, the level of UV radiation can reach extreme values causing UV indexes above 15. Maximum levels of $1490 \mathrm{~W} / \mathrm{m}^{2}$ were detected for global radiation and in the case of UV radiation, $72 \mathrm{~W} / \mathrm{m}^{2}$.

The occurrence of UV radiation enhancement effect above clear sky model, during the year, is much lower than the occurrence of global solar radiation enhancement, but still quite significant in relation to the number of 1 -minute events (68.904 versus 17.593). The phenomenon occurs in several months, reaching two seasonal peaks centered in March and October, when the weather conditions on the region are in transition from dry weather to a period of intense precipitation or vice versa. The duration of consecutive events of UV enhancement is between 3 and 13 minutes. These levels of UV radiation reach significant values whose levels may already cause harmful effects to living beings and materials exposed to this radiation. 
TABLE 4: Consecutive minutes $\left(\Delta T_{\max }\right)$, maximum deviation $\left(\Delta_{\max }\right)$, and maximum value of UV radiation $\left(\mathrm{UV}_{\max }\right)$.

\begin{tabular}{lcccccccccccc}
\hline & January & February & March & April & May & June & July & August & September & October & November & December \\
\hline$\Delta_{\max }$ & 3.90 & 3.87 & 6.21 & 2.74 & 6.36 & 3.27 & 3.90 & 3.45 & 7.89 & 6.55 & 4.60 & 6.30 \\
$\Delta T_{\max }$ & 6 min. & 7 min. & 5 min. & 4 min. & 5 min. & 11 min. & 7 min. & 3 min. & 4 min. & 5 min. & 6 min. & 13 min. \\
$\mathrm{UV}_{\max }$ & 61.96 & 54.39 & 70.39 & 59.78 & 59.2 & 43.44 & 45.47 & 60.77 & 50.41 & 66.56 & 66.28 & 61.49 \\
\hline
\end{tabular}

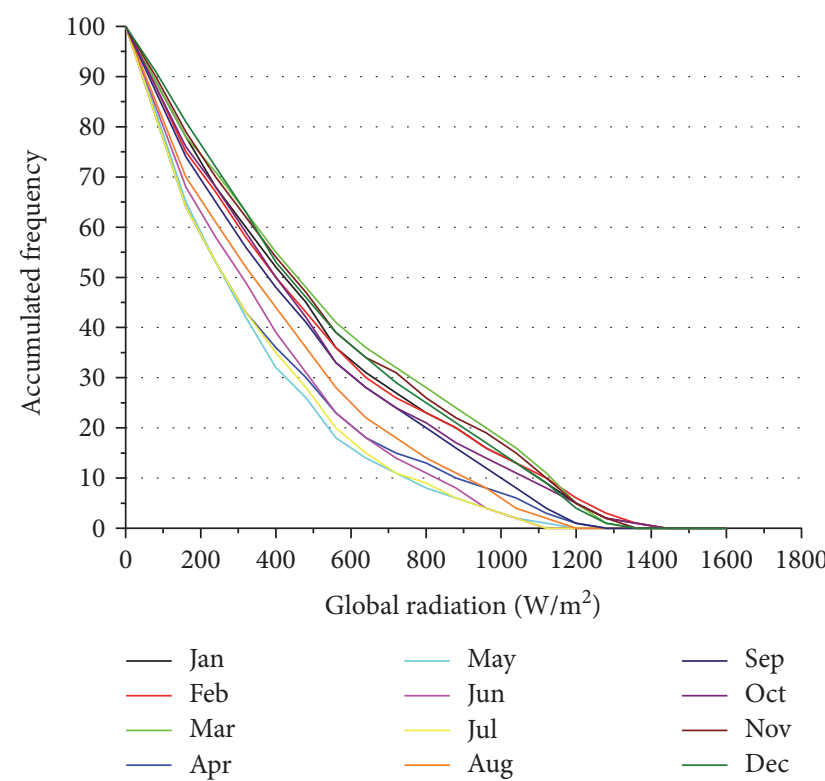

(a)

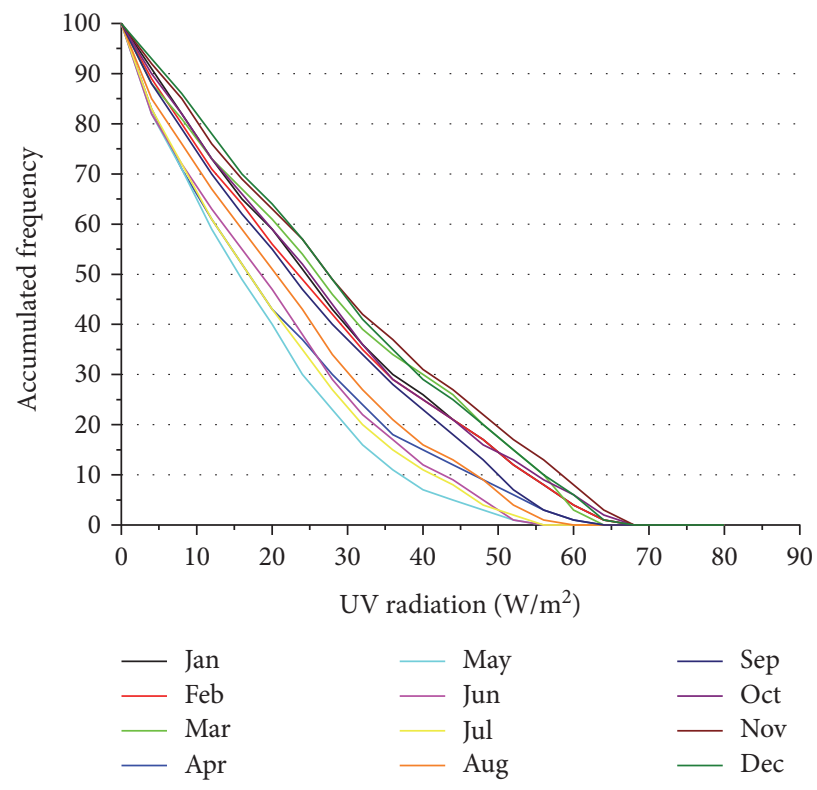

(c)

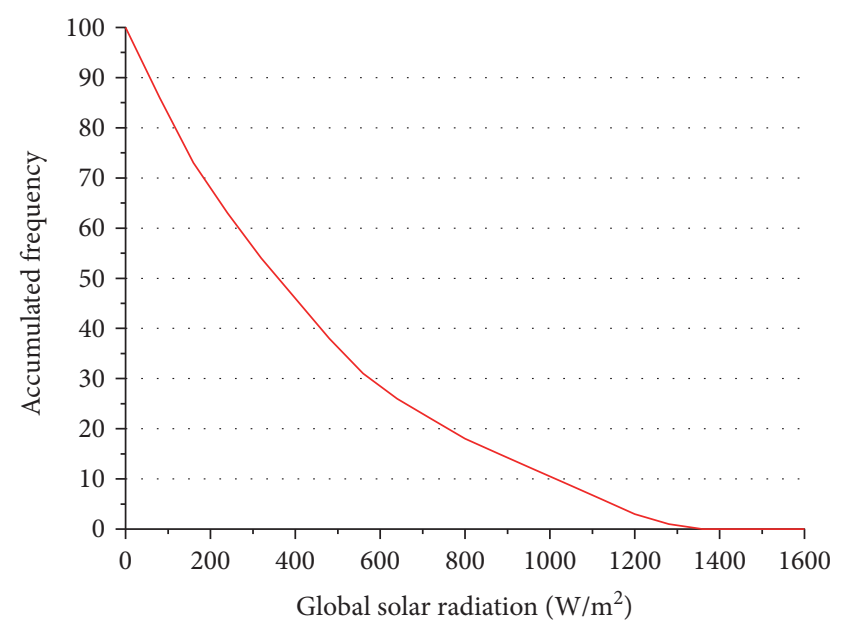

(b)

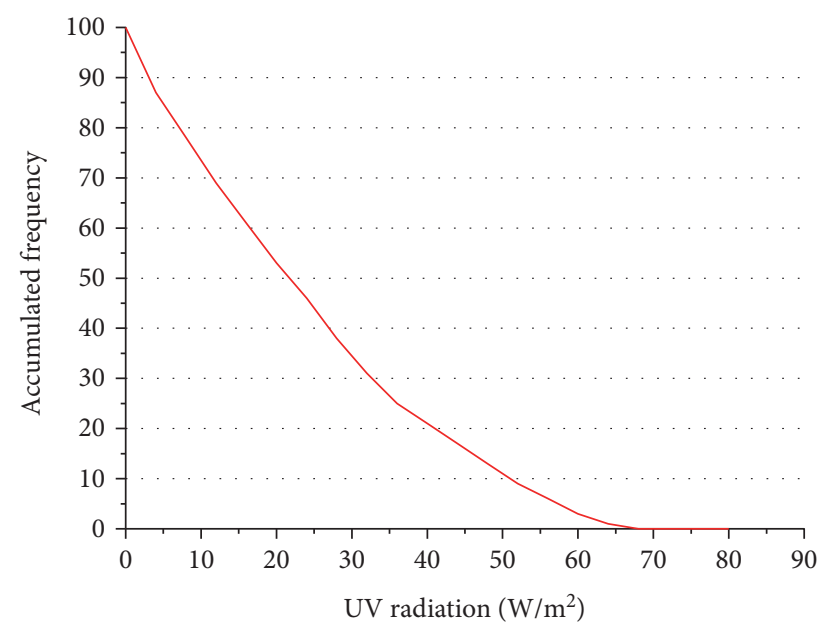

(d)

Figure 6: Monthly (a and b) and annually (c and d) accumulated distribution of global solar and UV radiation.

The correlation in minute scale between UV $(A+B)$ and global radiation made the generation of two statistical models for the estimation of UV radiation in the city of Recife, Brazil: the first to estimate UV radiation in normal conditions and the second to estimate the level of UV radiation in the occurrence of cloud enhancement effect, for the situation in which the levels of global radiation surpass the average $1367 \mathrm{~W} / \mathrm{m}^{2}$. It is 


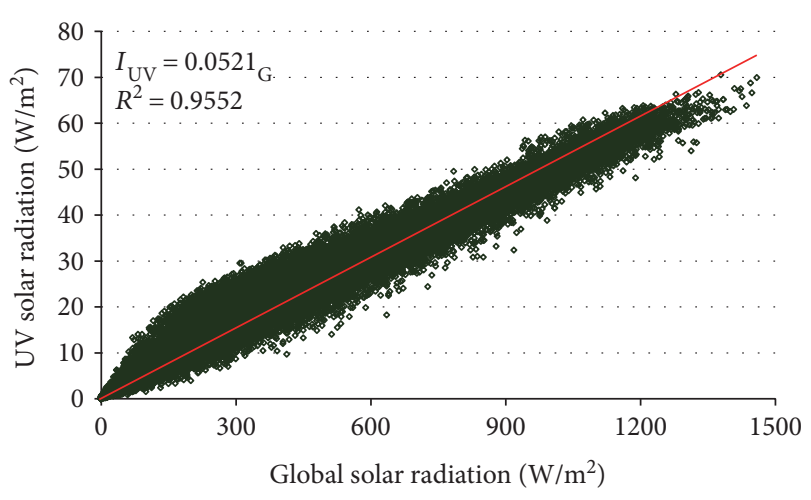

FIGURE 7: Correlation between the UV radiation in function of global radiation for the city of Recife.

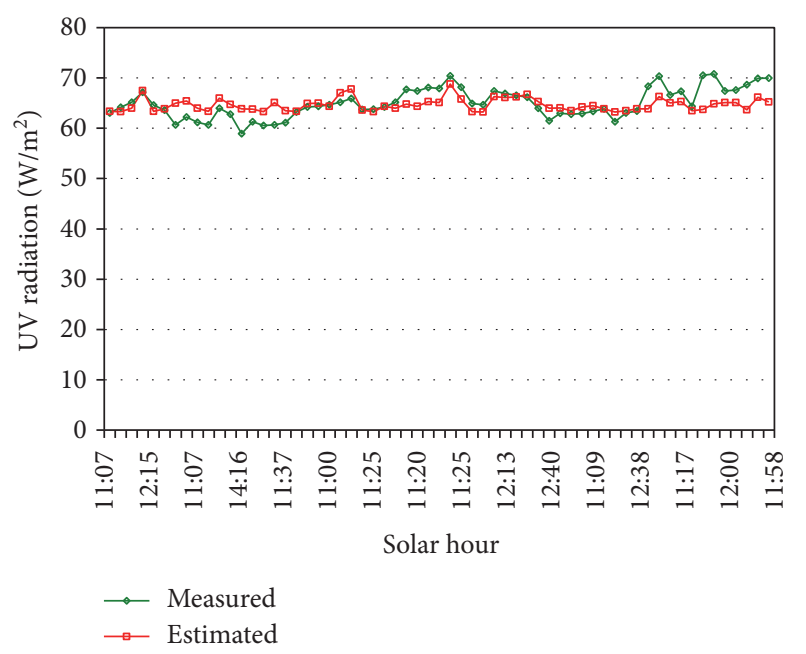

Figure 8: Comparison between the values estimated by the model and the experimental values.

worth noting the need of more larger number of measurements to improve the statistical validation of the model. However, the same showed an acceptable prediction accuracy for UV radiation in minute scale, when taking into consideration the precision of the equipment involved. The indicatives for both models presented, respectively, a MBE\% of 3.09 and $0.48 \%$ and a RMSE\% of 15.80 and $3.90 \%$. The use of these models with the knowledge of global radiation, measured or estimated, will allow the knowledge of the corresponding value of UV $(A+B)$ radiation, in minute scale for the city of Recife and regions with similar phytogeographical conditions. Therefore, it becomes another tool to subsidize the new educational public campaigns with new information regarding the risks and damages caused by excessive exposure to this radiation.

\section{Conflicts of Interest}

The authors declare that there is no conflict of interest regarding the publication of this paper.

\section{References}

[1] M. P. Corrêa, A divulgação do índice ultravioleta como prevenção ao excesso de exposição ao sol: uma contribuição da meteorologia para o desenvolvimento de políticas públicas para a saúde no País, XIII Congresso Brasileiro de Meteorologia, Fortaleza, 2004, Anais. CD-ROM (2004a).

[2] World Health Organization 2014-WHO, "Prevention of Blindness and Visual Impairment," http://www.who.int/ blindness/causes/priority/en/index1.html.

[3] Inca 2016-Instituto Nacional do Câncer, "Incidência de câncer no Brasil," 2016, http://www.inca.gov.br/estimativa/2016.

[4] P. RDG. M. Salum, N. Fraidenraich, and C. Tiba, "Extreme total solar irradiance due to cloud enhancement at sea level of the NE Atlantic coast of Brazil," Renewable Energy, vol. 36, pp. 409-412, 2011.

[5] A. RC and C. Tiba, "Extreme global solar irradiance due to cloud enhancement in northeastern Brazil," Renewable Energy, vol. 86, pp. 1433-1441, 2016.

[6] WMO, "WMO guide to meteorological instruments and methods of observation," 2010, 2008 edition, updated in 2010, February 2014, https://www.wmo.int/pages/prog/ gcos/documents/gruanmanuals/CIMO/CIMO_Guide-7th_ Edition-2008.pdf.

[7] EPPLEY160919-GPP (global precision pyranometers, specifications)," July 2017, http://www.eppleylab.com/instrumentlist/global-precision-pyranometer.

[8] EPPLEY160919-TUVR (Total ultraviolet radiometers, specifications)," July 2017, http://www.eppleylab.com/instrumentlist/total-ultraviolet-radiometer.

[9] I. Foyo-Moreno, J. Vida, F. J. Olmo, and L. Alados-Arboletas, "A simple all weather model to estimating ultraviolet solar radiation (290-385 nm)," Journal of Aplied Meteorology, vol. 38, pp. 1020-1026, 1998.

[10] R. SM, "A study of ultraviolet solar radiation at Cairo urban area, Egypt,” Solar Energy, vol. 77, pp. 251-259, 2004.

[11] R. Bird and C. Riordan, "Simple solar spectral model for direct and diffuse irradiance on horizontal and tilted planes at the earth's surface for cloudless atmospheres," Solar Energy, vol. 25, pp. 87-97, 1986.

[12] E. JF, E. N. Gomes, A. D. Pai, A. P. Oliveira, and J. Soares, Equações de estimativa diária para as radiações $U V, P A R e$ IV em função da radiação global para cobertura atmosférica parcial total, I CBENS-Congresso Brasileiro de Energia Solar, Fortaleza, 2007.

[13] B. Molineaux, P. Ineichen, and N. O'neil, "Equivalence of pyrheliometric and monochromatic aerosol optical depths at a single key wavelength," Applied Optics, vol. 37, pp. 70087018, 1998.

[14] C. Tiba and V. M. Pimentel, Estimating Atmospheric Linke Turbidity Index from Climatic Data for Pernambuco, ISES Solar World Congress 2009, Johnnesburg-South Africa, 2009.

[15] E. TF et al.B. J. Holben, J. S. Reid, O. Dubovik et al., "Wavelength dependence of the optical depth of biomass burning, urban, and desert dust aerosols," Journal of Geophysical Research, vol. 104, pp. 31333-31349, 1999.

[16] C.E.C, European Solar Radiation Atlas: Vols. I and II. EUR 9344 and 9345, Verlag TUV Rheinland, 1984.

[17] C. Tiba and S. S. Leal, Modelagem do IUV a partir da irradiação UV $(A+B)$ em Recife (PE), IV Congresso Brasileiro de Energia Solar, São Paulo, 2012. 

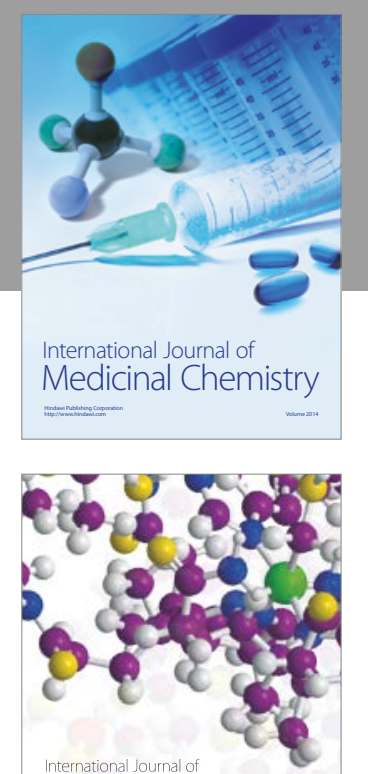

Carbohydrate Chemistry

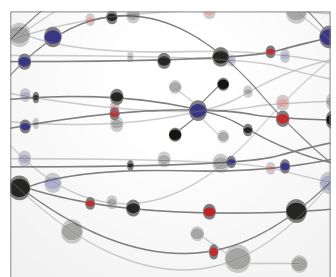

The Scientific World Journal
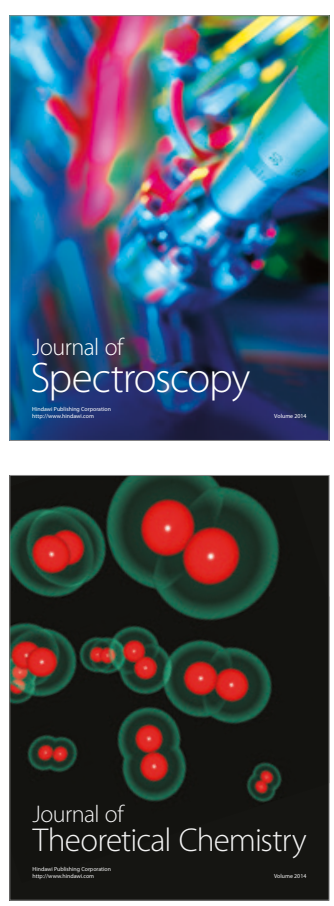
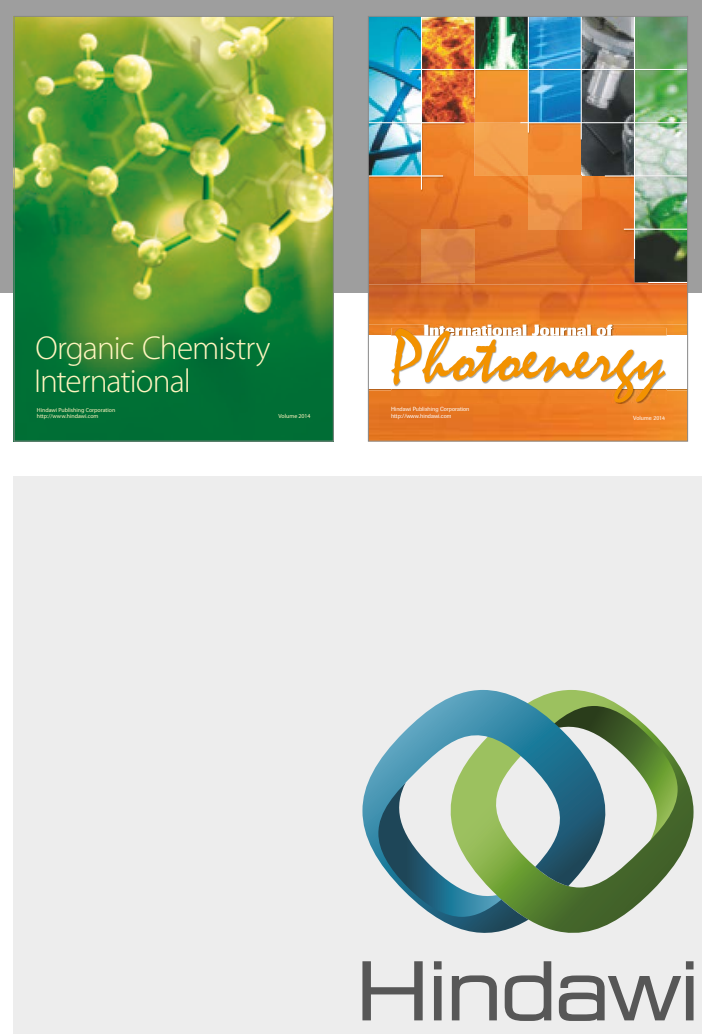

Submit your manuscripts at

https://www.hindawi.com

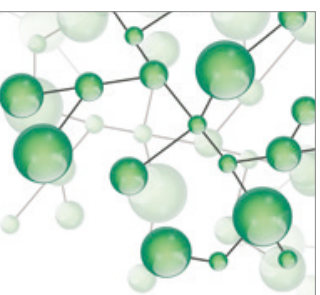

International Journal of

Inorganic Chemistry

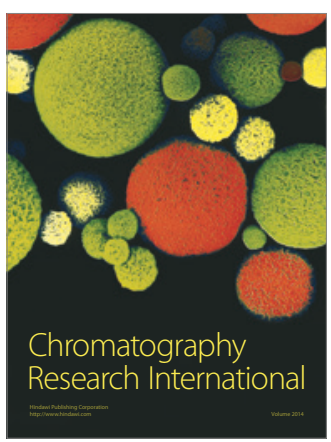

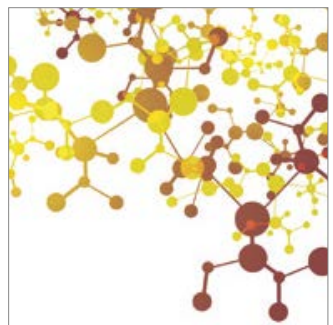

Applied Chemistry
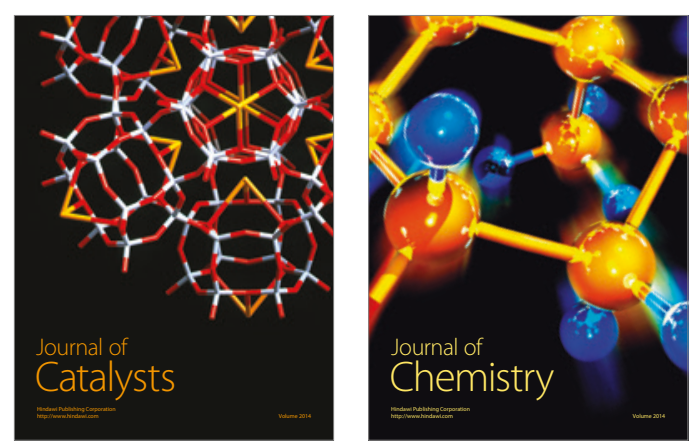
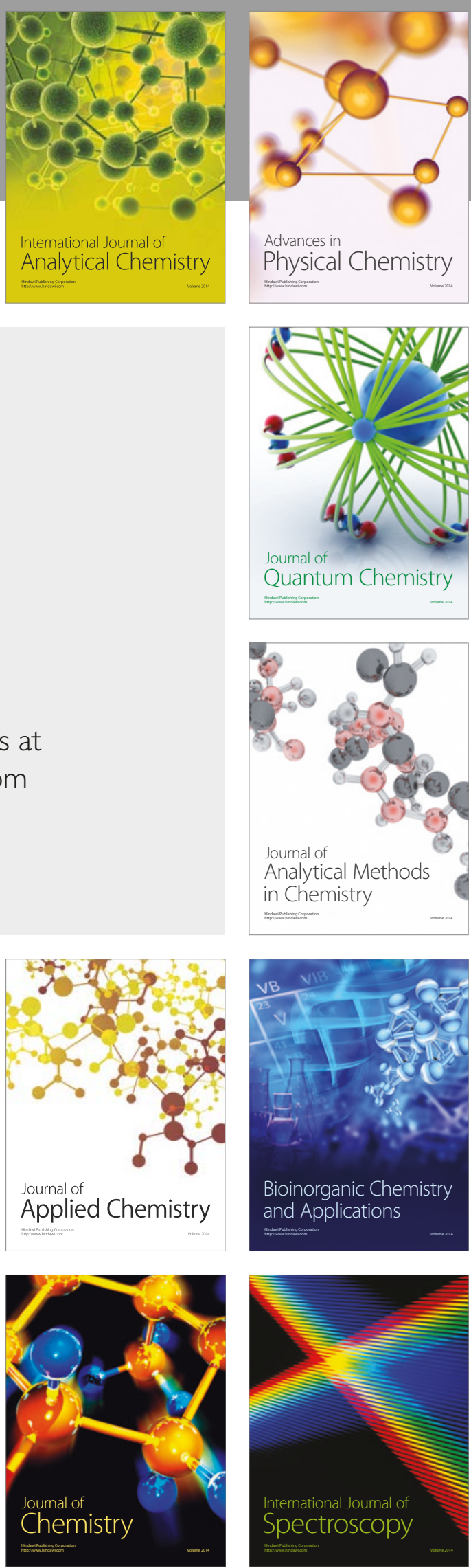